\title{
El breve, pero fructífero, apostolado de Martín Sarmiento de Hojacastro como Obispo de Puebla y su defensa de los indígenas frente a los encomenderos \\ The Brief but Fruitful Apostolate of Martin Sarmiento de Hojacastro as Bishop of Puebla and his Indian Defense against the «Encomenderos»
}

\section{Juan Pablo Salazar Andreu}

Universidad Popular Autónoma del Estado de Puebla MÉXICO

salazarandreu@yahoo.com.mx

[Hipogrifo, (issn: 2328-1308), 5.2, 2017, pp. 507-518]

Recibido: 04-11-2016/Aceptado: 28-12-2016

DOI: http://dx.doi.org/10.13035/H.2017.05.02.30

Resumen. Junto con otros religiosos de la orden de San Francisco, y con el apoyo del ejemplar Juan de Zumárraga, fray Martín Sarmiento de Hojacastro, no tan sólo se convertiría en Comisario General de la Orden de San Francisco en la Nueva España, sino que además se convertiría en titular del Obispado de Tlaxcala Puebla, iniciando una dura lucha en contra de los abusos de los encomenderos contra los indígenas. La presente investigación tiene por objetivo el mostrar, mediante el análisis histórico-jurídico y la técnica documental, parte de la labor de este eminente prelado en la conformación no sólo de la Ciudad de Puebla de los Ángeles, sino de la protección de los indígenas.

Palabras clave. Puebla; Martín Sarmiento de Hojacastro; protección indígena; obispado; Nueva España.

Abstract. Along with other religious from the Order of San Francisco, and with the support of the exemplary Juan de Zumarraga, fray Martin Sarmiento de Hoja- 
castro, not only would become General Commissioner of the Order of San Francisco in the New Spain, but it also become titular of the Bishopric of Tlaxcala Puebla, initiating a tough fight against abuses of the encomenderos over the Indians. This research aims to show, by the historical and legal documentary technique, part of the work of this eminent prelate in shaping not only the city of Puebla de los Angeles, but his protection of indigenous.

Keywords. Puebla; Martín Sarmiento de Hojacastro; Protection of natives; Bishop; New Spain.

\section{INTRODUCCIÓN}

Tres años después de la caída de Tenochtitlán en 1521 frente a las fuerzas castellanas, la llegada de los denominados «Doce apóstoles de México», franciscanos que, con el permiso de la Corona, tenían por objeto la evangelización de los nativos, permitió propagar la fe católica en el territorio descubierto, así como proteger a los nativos, de muchos de los abusos de los encomenderos, quienes, ávidos de riqueza, podían sobre-explotar a los indígenas. Los franciscanos en mención fueron:

- $\quad$ fray Martín de Valencia

- Francisco de Soto

- Martín de Jesús (o de la Coruña)

- Juan Juárez

- $\quad$ Antonio de Ciudad Rodrigo

- Toribio de Benavente (Motolinía)

- García de Cisneros

- $\quad$ Luis de Fuensalida

- Juan de Ribas

- $\quad$ Francisco Jiménez

- $\quad$ Andrés de Córdoba

- Juan de Palos ${ }^{1}$

La labor de estos admirables hombres y de aquellos religiosos que le siguieron, cosechó, mediante el establecimiento de monasterios, y el ejemplo de trabajo y virtud que mostraron siempre, muchos frutos en lo espiritual, pero también en lo político, ya que gracias a ello, las autoridades novohispanas, concedieron a los Franciscanos el gobierno de las nacientes mitras americanas; siendo ejemplo de ello el Episcopado de México-Tenochtitlán, que se le otorgó a fray Juan de Zumá-

1.Ver Iraburu, Hechos de los apóstoles en América, concretamente el capítulo dedicado a «Los primeros franciscanos de México». 
rraga, el Obispado de Tlaxcala, concedido a fray Julián Garcés y el Obispado de Michoacán que se otorgaría al Tata Vasco de Quiroga.

Pero estos dominicos, agustinos y franciscanos, se impusieron la notable e impresionante labor de defender a los oriundos de los territorios americanos, contra los abusos del conquistador, defendiendo un concepto, que si bien no se encontraba ya presente en la época, sí poseía ya un rango de comprensión espiritual: los derechos humanos. Los humildes, pero jurídicamente preparados frailes, se opusieron vehementemente a autoridades y encomenderos, creando fuerte pugnas entre Iglesia y peninsulares.

En este marco de lucha por los derechos humanos de los indígenas, se desempeñó como tercer obispo de Tlaxcala, el Monseñor Martín Sarmiento y Hojacastro, quien acordé a Shäfer², desarrolló su labor entre 1548 y 1557, fechas que disputa Fernández Echeverría y Veytia ${ }^{3}$, que señalan los años de 1546 y 1558 como aquellos en los que desarrolló su labor Sarmiento.

Nacido en el pueblo de Hojacastro, en los dominios de Castilla, y cercano a Santo Domingo de Calzada (hoy en día, la zona pertenece a la comunidad de La Rioja), a inicios del siglo XV, el futuro monseñor y tercer Obispo de Tlaxcala, era de origen noble y con importantes valores que le fueron inculcados desde su niñez ${ }^{4}$.

Desde su tierna edad fue inclinado a toda virtud, y frecuentaba las iglesias y oía en ellas con toda voluntad y atención las misas y la palabra de Dios. Y como profetizando cuán grande predicador y prelado había de ser, cuando volvía a su casa después del sermón, se subía en una silla y predicaba a su hermana mayor y a otras de casa el sermón que había oído y encomendado a la memoria. Y acabada su plática y decía a su hermana que le besase la mano, porque había de ser obispo (como también se lee de San Ambrosio que hacía lo mismo), y no queriéndolo hacer la hermana, por fuerza le ponía la mano en la boca, por lo cual muchas veces fue azotado por ella 5 .

El profundo espíritu religioso del hogar familiar, tuvo fuerza decisoria para que Martín optara por la vida al servicio de Dios, y a los 15 años de edad, tomó el hábito franciscano en el Convento de San Bernardino de la Sierra, ubicado cerca de Fresnada, en la Provincia de Burgos, actualmente Junta de Castilla y León. Tras su noviciado, reforzó su formación con estudios en teología y artes, destacando por su inteligencia, capacidad musical (siendo diestro en canto y órgano), y por sus cualidades como predicador. Finalmente a los 22 años de edad se ordenó sacerdote, y marcharía a Valladolid, sin imaginar que sus principales frutos serían cosechados en otro lado muy lejano del mundo, especialmente después de escuchar la teología del doctísimo padre fray Juan de Gaona, tomando entonces la resolución de partir con él y otros religiosos a la Nueva España en 1538; ; lugar al que llegaría con más

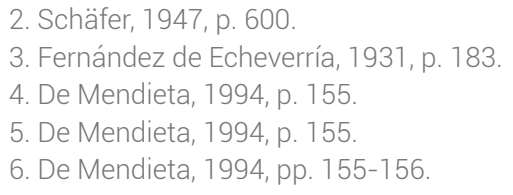


de treinta años, con una envidiable preparación espiritual y cultural, una disciplina férrea, y la compañía de fray Juan de Gaona, religioso ejemplar, formado en París, lo mismo que Julián Garcés.

El cambio de una rígida vida monacal, que desarrollaba gran parte de su tiempo en el convento, contrastaba enormemente con su nueva misión de evangelización y defensa de los débiles indígenas en un vasto territorio cuya extensión sorprendió a los colonizadores.

Coincidiendo con el mandato virreinal de Antonio de Mendoza, inició sus labores en la Nueva España. fray Martín fungió como compañero y secretario del Comisario General, fray Juan de Granada, a quien acompañó en su visita a la provincia franciscana de Michoacán. El recorrido por esta vasta región la hicieron a pie los dos religiosos, descubriendo las duras condiciones a las que debían enfrentarse los franciscanos en esa zona, así como los nativos para sobrevivir; sin embargo, el ingenio humano y la fe fueron las principales herramientas con las que aquellos que buscaban evangelizar a los "infieles", consiguieron sus objetivos; además también de enfrentarse a la voracidad de los encomenderos y autoridades novohispanas, cuyas acciones amenazaban siempre tanto la paz, como al proyecto de evangelización?

En el año de 1541, gracias a su trabajo, y a la confianza que le tenían los demás franciscanos de la Provincia del Santo Evangelio, y con el carácter de provincial, iría a Mantua (hoy Mantova, Italia), al capítulo general, en compañía del fray Jacobo de Testera, en caso de que, si muriese éste último, Martín lo supliera, representando a los franciscanos del nuevo continente.

Ya en Mantua, Jacobo de Testera recibió del ministro general de la orden franciscana, la designación como comisario general franciscano para Nueva España y Perú, mientras que Sarmiento, quedaría en una suerte de interinato a la muerte de éste, si el fallecimiento ocurría dentro de los seis años del generalato ${ }^{8}$. Así pues, ambos religiosos volverían a atravesar el Atlántico para cumplir su encomienda. Sin embargo, el destino ya estaba marcado para Sarmiento de Hojacastro, ya que fray Jacobo moriría poco después de la llegada a la Nueva España, dejando al biografiado como máxima autoridad franciscana en América, labor que desempeñó activamente de 1540 a 1550, recorriendo y apoyando las provincias franciscanas de Michoacán y del Santo Evangelio. Precisamente, ésta última comprendía el vasto territorio del obispado de Tlaxcala-Puebla, en donde estaban asentados conventos de gran importancia como Tlaxcala, Huejotzingo, Tepeyanco, Puebla y Tepeaca. Mas en lo referente a Perú, la inmensa carga de trabajo del franciscano, le impidió trasladarse personalmente, por lo que, envió comisarios y visitadores al virreinato sudamericano ${ }^{9}$.

Siendo Comisario General Franciscano en la Nueva España, y en comunión con el extraordinario fray Juan de Zumárraga, arzobispo de México y el padre Francis-

7. De Torquemada, 1986, p. 518.

8. De Mendieta, 1994, p. 156.

9. De Mendieta, 1994, p. 156. 
co de Soto, en una misiva hasta ahora poco conocida que enviaran al emperador Carlos V, el 4 de octubre de 1543, durante la fiesta de San Francisco; expresaron el pensamiento de la Iglesia novohispana de la primera mitad del siglo XVI; reconociendo como patrono de la misma al Emperador, y enarbolando los conceptos de «nación española» y «nación indígena» (un anticipado ideal de México). Así también solicitaron leyes justas para los naturales del continente, denunciaron los abusos de encomenderos y autoridades novohispanas, pero reconocieron igualmente la labor del Virrey Mendoza ${ }^{10}$. Tal relevancia tiene el documento en cuestión, que su reproducción es indispensable en el presente estudio:

\section{A Su Sacra Cesarea Católica Majestad ${ }^{11}$ :}

Dos cosas entendemos que Vuestra Majestad quiere de nosotros; la primera es que roguemos a Dios Nuestro Señor, por prósperos sucesos a tan grandes, difíciles e importantes cosas como ahora tiene entre las manos, tocantes a toda la Iglesia Universal más allá de estas tierras. En esto, nos amonesta el apóstol San Pablo, en la primera epístola donde señala: «Obsecro igitur primo oum fiesi obsecrationes, postulationes, gray actiones, pro regibus et pro omnibo qui in sublimitate sunt constituti ut quietam et tranquillamvitam agamus. In omni pietate et castitate hoc bomie, et acceptu cora Salvatore nro deo. Y antes del aduenimiento de Christo estatua escripto en el propheta Baruch p.c. Orate pro vita Nabuchdonosoz regis Babilonis, et provita Balthasar filij eisus ut sint dus cozc sicut dies celi super terra».

Si por los príncipes infieles, que entonces regían al mundo, la sagrada escritura del Nuevo y el Viejo Testamento de la primitiva Iglesia, exhortaba a los fieles a hacer oración por ellos; cuanto más nosotros debemos considerarnos exhortados y obligados a ofrecer nuestras oraciones por un príncipe tan cercano al cristianismo; el cual, junto con otros trabajos y cuidados, la divina clemencia, se ha complacido en señalar como vicario en lo temporal de esta tierra y por patrón de ésta, su nueva Iglesia; la cual siempre ha mirado y favorecido Vuestra Majestad, y que ahora, creemos, convertirá su corazón a considerar con mayor familiaridad las cosas que ocurren en este reino, para remedio y sosiego del mismo.

En segundo lugar, creemos que Vuestra Majestad requiere de nosotros, noticias de las cosas que aquí suceden, siendo en esta coyuntura, donde más se ha sentido los movimientos y traslados recientemente sucedidos, desde los últimos capítulos y ordenanzas reales; y por servir a Vuestra Majestad, y dar algún alivio y consuelo a los leales vasallos que Vuestra Majestad en estas partes tiene, por lo cual acordamos poner la mano a la pluma.

Muchos años se ha presupuesto la necesidad que esta tierra tiene de españoles; de manera similar, a la que tiene la carne del cuerpo humano de los huesos para sostenerse, y los huesos de la carne para ser cubiertos por ella. Los españoles serían a nuestra consideración los huesos, pues son la fortaleza y varonil fuerza de esta tierra; los indios, son la carne flaca. Entre estos se requiere grandes lazos y vínculos de amor; de las que depende todo el bien de esta Iglesia, así en

10. Carta del Arzobispo de México y padres franciscanos al emperador, 4 de octubre de 1543; Diversos, Legajo 22, núm. 45, AHN.

11. El documento se ha actualizado a una versión de castellano moderno, para una mayor facilidad de lectura y comprensión del mismo. 
lo espiritual como en lo temporal; bien aventurado será el que llevare a estas dos naciones a ese vínculo de amor.

Mas la astucia del demonio no cesa en crear disensión.

Es común y natural que los españoles presenten tres cualidades: primero, ser ejemplo de buena cristiandad; lo segundo, buen trato similar al de padres a hijos y, lo tercero, ser recatados, de tal forma, que no se dé ocasión, de que viendo descuidados a los españoles, el demonio les ponga en el corazón sentimientos o emociones que le convengan; porque el agujero llama al ladrón, y esto no es favorable, ni para los indios, ni para los españoles, ya que «poder pecar, no es libertad, ni cualquier forma de ella».

El ser recatados y guardados, es una bien aventurada necesidad, para un fin muy deseado: que los indios se acerquen a la Iglesia, la cual ya alcanzaron los españoles. Y así como el agua da vida, los huesos y la carne juntos, pueden crear la fe que, formada e inflamada de caridad, estuviere tanto en unos, como en los otros, y los hiciere una misma cosa. Porque parece horrible que los huesos despedacen su propia carne, y que la carne se aparte de los huesos.

Con el fin mencionado, es menester dar asiento en la tierra, para que los españoles tengan reposo y arraigamiento perpetuo en ella; para que esta tierra les sea madre y ellos hijos que la amen, honren y defiendan. Pero este reposo y arraigamiento, les ha de venir no solamente de la bondad y fertilidad de la tierra; y a Vuestra Majestad, no deben convencer de que ello basta; porque todos los que acá pueblan, deben tener anexo el cuidado y apercibimiento de la defensa de la tierra.

Pero para ese objetivo, deben respetarse ciertos principios, que es el favor del príncipe, consistente en hacer mercedes perpetuas, sin distinción de personas mayores, medianos o menores, según lo requiera la justicia distributiva que, cerca del cuerpo político, conforman a la República; donde si bien no conviene que todos sean iguales, se deben observar como al cuerpo humano, en el que existen miembros distintos, y cuya cabeza es el príncipe. Vuestra Majestad favorezca mucho a estos miembros de este cuerpo político y como tales reciban vida y favor de su real mano, pues es la cabeza y principio de donde les ha de venir todo bien; y como los españoles son los brazos de este cuerpo, si de la cabeza no les viene la fuerza, serán brazos secos y sin virtud. Pero con el favor que Vuestra Majestad otorgue a esta correspondencia, la cabeza dará fuerza a los brazos, y los brazos defenderán la cabeza y el cuerpo de la República.

También nos parece que, en relación a la seguridad de la tierra, Vuestra Majestad debe otorgar a los naturales, algunas cosas de estas ordenanzas que recomendamos; las cuales hacen a su favor y propósito, para que, junto con los españoles, en la caridad que hemos dicho, puedan resistir a quienes les quieran tiranizar, ya sean fieles o infieles, que pretendiesen tomar estas tierras o hacer daño en ellas. La sospecha de esto, reside en la fama que esta tierra tiene en el mundo conocido, siendo considerada muy rica. Aún no sabemos si así les consta, ya que, desde el principio, nunca se le resguardó como hubiera sido conveniente. Afortunadamente la gracia de Dios lo ha remediado fuertemente, mediante aquellos que él sabe que se han de salvar.

Pero según la doctrina de los teólogos, la confianza que se ha de tener en Dios, debe preceder a toda diligencia humana, por lo que es nuestro deber, que los naturales conozcan a Dios, y que sepan que Vuestra Majestad los ama, y les tiene la 
misma afección de verdadero señor y padre, que a los españoles; procurando saber cómo les va y cómo son tratados; compadeciéndose de ellos como sus verdaderos vasallos; lo cual permitirá, que cada vez que se sientan agraviados, acudan antes al amparo y protección de Vuestra Majestad, que a las armas. Esto conviene mucho no sólo a ellos, si no más aún a los españoles. Nosotros los religiosos, nos sentiremos también llenos de gozo, cuando así lo sientan ellos, de Vuestra Majestad. Esto es lo que acerca la pacificación de estas tierras, y aumento de la Corona Real y arraigamiento y población, de muchos en estas tierras.

Acerca de los españoles, hacemos saber a Vuestra Majestad, que les han causado grandes alteraciones y desasosiego las nuevas noticias, temiendo que, si son verdaderas, serán privados de las mercedes que Vuestra Majestad les tenía hechas. Sospechamos que están desconfiados, provocando que, en ésta tierra, no tengan ni hijos, ni prosperidad. No nos atrevemos a considerar, que Vuestra Majestad no haya pensado en el medio para asegurar la tierra, por lo que nos sentíamos acobardados al escribir a Vuestra Majestad, sino hasta ver la última resolución autorizada; y así en esto que, ahora escribimos, no pretendemos obviar, argumentar, ni menos enmendar lo que acá se dice que Vuestra Majestad ha mandado; porque nos consta el celo con que Vuestra Majestad se habrá movido, tomando consejo y pareceres de tantas y tan calificadas personas, para determinar y proveer, pero no dejaremos como fieles vasallos y capellanes continuos, que en espíritu andamos siempre al lado de Vuestra Majestad, en los grandes trabajos que continuamente padece por la Iglesia de Dios, como a nuestro natural Rey y Señor; significarle lo que en esto sentimos.

El sentimiento que tenemos acerca de las cosas que Vuestra Majestad ordena, es que las mercedes que ha hecho a los de acá, las miramos con ojos limpios y sinceros; así, cuando las hace como cuando las tiempla; por eso nunca hemos puesto escrúpulo en ellas; porque los méritos y servicios de cada uno, que mueven a Vuestra Majestad a conceder mercedes, lo tiene cada uno en su pecho; y en fin, basta quererlo Vuestra Majestad, para que nosotros tengamos lo justo. Cualquier afirmación contraria, evidentemente no nos consta "qui quod principi plant leges hact vigorem nec oportet nos sapere plusq oportet sapere" y esto mucho menos en negocios particulares.

Cuanto lo que toca a la República, diremos lo que sentimos. Lo primero y principal, es que Vuestra Majestad debe proveer en breve, ordenes respecto al asentamiento perpetuo y estable de los españoles en esta tierra, los cuales son la fortaleza y seguridad de ella, presuponiendo siempre el divino socorro; porque mientras falte esta estabilidad, y ni estuvieren arraigados y fundados como naturales en ella, habrá menos provecho en lo espiritual y temporal. Pero, teniendo ellos posesiones y propiedades que les duela dejar y perder, y viniendo con alegría, a mantener lo suyo, defenderán todo lo demás; que es el Señorío de Vuestra Majestad, bien común de la República y provecho de nuestra tierra.

Mas como no sabemos lo que acerca de esto Vuestra Majestad tiene proveído, no nos atrevemos a dar parecer de las medidas más concebibles, hasta que nos consten, y entonces, mandándolo Vuestra Majestad, cada uno podrá manifestar su sentimiento.

$Y$ de quien mejor Vuestra Majestad puede tomar parecer en esto, y en todo lo demás que toca a esta tierra, si no es de su Virrey Don Antonio de Mendoza, de quien consta su buen celo y prudencia, cristiandad y larga experiencia; al cual 
Vuestra Majestad, debe dar crédito en todo lo que concierne a su servicio y al de Dios, y bien común de la tierra.

Lo segundo que nos parece, es que mientras Vuestra Majestad no provea otra cosa en el asiento perpetuo de la tierra, y respecto de la enmienda de Vuestra Majestad; lo que se dice de la Cédula se suspenda, y se esté como antes se estaba. Conviene saber lo que suceda al primer hijo heredero en los pueblos de los indios, conforme a la merced que Vuestra Majestad les ha hecho. A esto nos mueven algunas causas, entre otras, que no cesen los matrimonios que por la merced de la cédula aumentaron y así crezca la población de la tierra y se diriman y atajen muchos pecados.

Lo tercero que nos pareció señalar a Vuestra Majestad, es acerca de los corregidores, que, aunque se establecieron, y hubo razón para ello y coyuntura por donde realizarse, nos pareció que «em bien tame rebus existenti bus ut nunc», y por tanto, no conviene ahora de ninguna manera. Primero, por que como están divididos en diversas partes, todos no valen sino por uno, y así no hacen provecho de la seguridad de la tierra. Segundo, porque los indios no tienen necesidad de ellos. Lo último porque ellos no medran para sí mismos, ni acrecientan la República, ni la siembran, ni enriquecen como otros pobladores; porque van peregrinando de una provincia en otra, cesando en esto las mercedes que Vuestra Majestad les debe hacer para que sean remediados, ricos y honrados. Para que sirvan a las granjerías y población de la tierra y defensión de ella, es necesario estar juntos los unos con los otros, según que dice la escritura "terribilis ut castrozc aties ordinata", en lo cual se da entender que no será el ejército de temer si no fuere bien ordenado y estuvieren todos juntos.

También nos parece que así de los conquistadores, como de los pobladores, los que tuvieren para sustentarse, Vuestra Majestad los mande proveer, para que todos tengan amor a la tierra y trabajen y se arraiguen a ella.

Lo último, para la buena cristiandad, ejemplo y edificación, así de los naturales, como de los españoles, es que Vuestra Majestad ordene que los casados que vivan en esta tierra, y tienen las mujeres en España, que las traigan acá, so pena que pierdan las mercedes; y con esto se quitarán muchas ofensas a Dios.

Y con tanto, quedamos rogando a la divina bondad que estas cosas que aquí escribimos, no tengan más ni menos eficiencia en el corazón Real de Vuestra Majestad, de cuanto convenga a la plantación de esta Iglesia y honra y gloria de Dios, el cual guarde y prospere por largo tiempo a la muy Real e Imperial persona de Vuestra Majestad, para remedio y socorro de la necesidad que la sagrada Iglesia tiene.

De este su Convento de San Francisco de México, día de nuestro glorioso Padre de San Francisco de 1543.

fray Juan Obispo de México

fray Martín de Hojacastro, Comisario General

Hermano fray Francisco de Soto ${ }^{12}$. 
Sin duda alguna, los informes del clero regular y secular, así como la coherencia de sus exposiciones, influyeron para que el Consejo de Indias y el Emperador, aplicaran las Leyes Nuevas de 1544, cuyo contenido asestó un duro golpe a los encomenderos, quienes desde la década de los veinte del siglo XVI, se sentían intocables, y con la suficiente autoridad de abusar de los naturales, explotándolos física y laboralmente ${ }^{13}$.

Concluido ya su generalato, fray Martín planeó el regreso a Europa, para rendir cuentas de su gestión ante el capítulo general franciscano, y estando en el Puerto de Veracruz y listo a zarpar, una fuerte tormenta daría inicio, que terminaría por destrozar la embarcación en la que viajaría, y matar a muchos de los marineros. Este fenómeno, fue considerado por el religioso como una señal divina que lo forzaba a quedarse en tierras novohispanas, siendo nombrado poco tiempo después, en el capítulo de Texcoco, como guardián de Tlaxcala.

Fue designado como tercer titular de la Mitra de Tlaxcala-Puebla, cargo que aceptó no sin cierta resistencia, y gracias a la obediencia que le tenía a su provincial, el célebre fray Toribio de Benavente y con el beneplácito del Virrey de la Nueva España, don Antonio de Mendoza ${ }^{14}$.

mandóle entonces el santo fray Toribio hincar de rodillas, e hincado fray Martín, le preguntó si lo conocía por prelado. Y respondiendo fray Martín que sí, y que en ello se tenía por muy dichoso, replicóle entonces el santo vicario que pues lo tenían por prelado, le mandaba por santa obediencia, en virtud del espíritu santo, aceptase la voluntad de Dios: que él se ofrecía y los demás religiosos a encomendarlo a Nuestro Señor en sus sacrificios y oraciones. Aceptolo el electo obispo, diciendo que con los favores de la obediencia y oraciones de tales religiosos, él lo aceptaba. Lo cual dio gran contento a todos, en particular al prudentísimo don Antonio de Mendoza, Virrey de ésta Nueva España ${ }^{15}$.

Es digno de destacar que la armonía entre el virrey y los prelados novohispanos, permitieron de manera determinante enfrentar el poder de los encomenderos, conformando una confederación entre virrey, obispos y religiosos, que aplicaron en el nuevo continente, las Leyes Nuevas, situación muy diferente a la que se presentó en el Virreinato del Perú, en donde el Virrey Blasco Núñez murió el 18 de enero de 1546, en el combate contra Gonzalo Pizarro, en virtud de la aplicación de las leyes nuevas. Incluso, Carlo $V$, en conocimiento del talento y experiencia de Mendoza, lo envió al inquieto reino sudamericano en calidad de Virrey, para que controlase a los encomenderos rebeldes a las Leyes Nuevas ${ }^{16}$.

Contando entonces con poderosos aliados religiosos, de entre los que destacaba el titular de la Mitra poblano-tlaxcalteca, el Virrey Mendoza, enfrentó con gran éxito la oposición de los encomenderos.

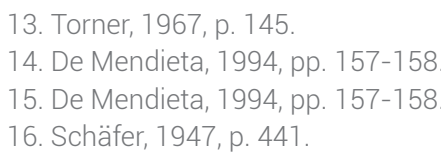


Al recibir Martín Sarmiento sus bulas como Obispo de Tlaxcala-Puebla, a finales de la década de 1540-1550, fue consagrado en Oaxaca por monseñor Juan López de Zárate, hacia 1548, toda vez que el obispo oaxaqueño, solicitó licencia para ausentarse de su obispado por dos años en $1546^{17}$.

Como si fuera un fraile de los comunes se partió luego para su obispado a pie, y pidió a los prelados de esta provincia que mientras le venían las bulas de Su Santidad, le diesen por maestro al muy docto y santo varón, fray Juan Fucher para que le leyese los sacros cánones, lo cual le concedieron. Y fuese al Convento de Cholula y vivió allí como uno de los frailes, haciéndose oyente del sobredicho padre ${ }^{18}$.

Cabe señalar que por esas fechas fallecería en España, el arzobispo de México, fray Juan de Zumárraga, el cabildo de México hizo la petición ante la autoridad real de que fray Martín Sarmiento de Hojacastro, fuese honrado con la mitra de la capital del virreinato; sin embargo, su destino estaba escrito: la sede angelopolitana necesitaba de un santo varón que continuase con las tareas emprendidas por el ejemplar Julián Garcés ${ }^{19}$.

Los pobladores de Puebla recibieron con gran alegría la noticia del nombramiento del prelado, tal como lo destaca el acuerdo del Cabildo Municipal de $1^{\circ}$ de enero de 1549, en el que se otorga una merced de ocho solares cerca de San Agustín al prelado, y el acuerdo de 27 de noviembre de 1551, en el que se le obsequian dos huertos, cerca de San Francisco, al pie del cerro ${ }^{20}$.

Señala Gibson que en 1549 se presentó un conflicto entre la provincia y el obispado, que tuvo como punto de partida el traslado de la sede episcopal a la Ciudad de Puebla, así como los tributos por manos de obra y diezmos, por lo que el prelado requirió de cuarenta obreros tlaxcaltecas, para la edificación de su casa en la Angelópolis, pese a la renuencia del Cabildo de Tlaxcala que sólo quería autorizar a veinte ${ }^{21}$.

Salta a la vista que las autoridades de la Ciudad de Tlaxcala tuvieron poco tacto político, mientras que las autoridades municipales poblanas otorgaron mayores facilidades para que la sede episcopal para no abandonase la urbe angelopolitana, que, tras dos décadas, había experimentado un gran crecimiento demográfico, político y económico. (Acuerdo de Cabildo, 26 de noviembre 1555; 16 de noviembre 1556, y 15 de junio 1556, AMP); Los obispos del siglo XVI Garcés y Sarmiento desarrollaron su labor, en perfecta armonía con las autoridades municipales de la Angelópolis. Debiendo destacarse, que el pontificado de Martín Sarmiento, mostró gran interés por los grupos marginados, presentándose como padre de pobres, a quienes les ayudaba y proveía al grado de decir «¿qué sentirá un obispo pobre que

17. Schäfer, 1947, p. 565

18. De Mendieta, 1994, p. 158

19. De Mendieta, 1994, p. 159.

20. Acuerdo de Cabildo, 7 de enero de 1549, vol. 6, documento 54, fol. 33v, AMP y Acuerdo de Cabildo, 27 de noviembre de 1551, vol. 6, documento 186, fol. 176v, AMP.

21. Gibson, 1991, p. 50. 
ve tantos necesitados, y tantas viudas y doncellas huérfanas, y no tiene con qué remediarlos» ${ }^{22}$.

El primer Concilio Provincial de la Iglesia Novohispana es el acontecimiento político y jurídico de mayor envergadura del obispado de Sarmiento, ya que reviste gran importancia en la evolución del clero en México, toda vez que los obispos novohispanos realizan el primer intento para controlar a las órdenes religiosas, debiendo resaltarse, que los actores más notables de este evento, eran miembros de dichas congregaciones, a saber: Montúfar y Sarmiento, quienes se vieron apoyados por el obispo de Chiapas fray Tomás de Casillas, también religioso dominico, y por el arzobispo de México, Vasco de Quiroga, pastor de Michoacán, y los representantes de las diócesis acéfalas. De ese concilio emanaron disposiciones tales como la prohibición a clérigos de ser prestamistas, mercaderes, jugar naipes, tablas y dados, así como la venta de sepulturas y prodigar excomuniones ${ }^{23}$. De esto cabe destacar que se presentó como un preámbulo al conflicto entre Palafox, la Compañía de Jesús, el Virrey, Alcaldes Mayores e Inquisición, con motivo de diezmos y reforzamiento del clero secular, debiendo señalarse que Montúfar pretendió aplicar sin éxito una sana supremacía de los obispos sobre el clero regular ${ }^{24}$.

En el Convento de la Orden de San Francisco, Sarmiento fallecería entre sus hermanos religiosos tal como lo deseaba ${ }^{25}$ a principios del mes de noviembre de 1558, llevando su cuerpo a su iglesia y siendo llorado por todos, especialmente por los indígenas a los que había entregado su trabajo y vida ${ }^{26}$.

\section{ABREVIATURAS}

AHN Archivo Histórico Nacional, Madrid.

AMP Archivo Municipal de Puebla.

\section{FUENTES MANUSCRITAS}

Archivo Histórico Nacional, Madrid, Legajo 22, núm. 45.

Archivo Municipal de Puebla (AMP) Volumen 6, documento 54, folio 33v; documento 186 , folio $176 \mathrm{v}$. Volumen 7, documento 77, folio 83v. Documento 90, folios 98v a 99v; documentos 95, folios 103 f-103v; documentos 115 folio 142v.

\section{BIBLIOGRAFÍA}

Cuevas, Mariano, Historia de la Nación Mexicana, México, Porrúa,1940. 
De Mendieta, Jerónimo, Vidas Franciscanas, México, UNAM, 1994.

De Torquemada, Juan, Monarquía Indiana, México, UNAM, 1986.

Fernández de Echeverría y Veytia, Mariano, Historia de la fundación de Puebla de los Ángeles en la Nueva España, México, Imprenta Labor, 1931.

Gibson, Charles, Tlaxcala en el siglo XVI, México, FCE, 1991.

Iraburu, José María, Hechos de los apóstoles en América. Disponible en línea: $<$ http://hispanidad.tripod.com/hechos8.htm> [10/10/2017].

Shäfer, Ernest, El Consejo Real y Supremo de las Indias, México, Carmona, 1947.

Torner, Florentino, Resumen Integral de México a través de los siglos. El Virreinato, México, Compañía General de Ediciones, 1967. 